TITLE:

\title{
LIFE HISTORY AND POPULATION FLUCTUATION IN THE LABRID FISH, LABROIDES DIMIDIATUS, NEAR THE NORTHERN LIMIT OF ITS RANGE
}

\author{
$\operatorname{AUTHOR(S):~}$
}

Kuwamura, Tetsuo

\section{CITATION:}

Kuwamura, Tetsuo. LIFE HISTORY AND POPULATION FLUCTUATION IN THE LABRID FISH, LABROIDES DIMIDIATUS, NEAR THE NORTHERN LIMIT OF ITS RANGE. PUBLICATIONS OF THE SETO MARINE BIOLOGICAL LABORATORY 1981, 26(1-3): 95-117

\section{ISSUE DATE:}

1981-03-30

URL:

http://hdl.handle.net/2433/176021

RIGHT: 


\title{
LIFE HISTORY AND POPULATION FLUGTUATION IN THE LABRID FISH, LABROIDES DIMIDIATUS, NEAR THE NORTHERN LIMIT OF ITS RANGE ${ }^{1)}$
}

\author{
Tetsuo KUWAMURA ${ }^{2)}$
}

Seto Marine Biological Laboratory

With Text-figures $1-10$ and Tables $1-4$

\begin{abstract}
The ecology of the Indo-Pacific tropical labrid fish, Labroides dimidiatus, was studied at the shallow rocky reefs in Shirahama, near the northern limit of its distribution. The population increases in late summer and autumn when juveniles are recruited, but considerably decreases in winter, when water temperatures decline as low as $10^{\circ} \mathrm{C}$. The fish are socially and sexually active only in the warmer period, from April to November or December, and spawning occurs restrictedly within 4-5 months from late May to early September. Juveniles settle out of the plankton, probably within one or two months after spawing. The rapid growth of juveniles in summer and autumn makes up for the low growth in the next winter, and subsequently the one-year old fish are matured, usually as females, in the next breeding season. Though protogynous sex-change usually occurs shortly before 3-years old, even the one-year old fish can become a male when there are no older or larger individuals in its vicinity. The adult population declines also in late summer and early autumn, coincidentally with the beginning of the juvenile recruitment. The life history pattern of $L$. dimidiatus in Shirahama is compared with those in southern localities, for which information is available, and the modifications in the life history pattern are discussed in relation to the fluctuation of population.
\end{abstract}

Labroides dimidiatus (Valenciennes) is one of the five species of the genus Labroides (Pisces; Labridae), all of which are well known as cleaner fish that remove food items such as ectoparasites from the body of host fishes (Randall, 1958; Randall and Springer, 1975). It is the most common and widespread of the genus, extending its range from East Africa across the Indian Ocean and well into the Pacific, being especially common in tropical coral areas (Randall, 1958).

The ethology and ecology of $L$. dimidiatus have been intensively studied at Heron Island on the Great Barrier Reef (Robertson, 1972, 1974; Robertson and Choat, 1974; Robertson and Hoffman, 1977), and considerably at Aldabra Island in the western Indian Ocean (Potts, 1973; Robertson and Hoffman, 1977). Robertson found that the social control of protogynous sex-change occurred within social groups comprising a male and a harem of several females living in the male's territory (Robertson, 1972, 1974; Robertson and Choat, 1974).

In the vicinity of Japan, L. dimidiatus commonly occurs in the southern coral

1) Contributions from the Seto Marine Biological Laboratory, No. 669.

2) Present address: Faculty of Liberal Arts, Chukyo University, Yagoto-honmachi, Nagoya, 466.

Publ, Seto Mar, Bịol, Lab,, XXVI(1/3), 95-117, 1981, (Article 4) 
areas of the Ryukyu Islands and Ogasawara Islands (Yoshino et al., 1975; Kataoka et al., 1970), and extends its range northward up to the Tsushima Islands on the coast of the Japan Sea (Kimura, 1965) and Kominato, Chiba Prefecture on the Pacific side (Nakamura, 1934). In Shirahama, on the southern Pacific coast of Honshu Island, where the present study was carried out, L. dimidiatus is distributed therefore to occupy near by the northern limit of its range. Influenced by the branching current of the Kuroshio, there is a rather rich fish fauna, although it tends to be poor in winter when the water temperature lowers as low as $10^{\circ} \mathrm{C}$ (Okuno, 1964; Araga and Tanase, 1966, 1968; Kuwamura, 1976a, 1980b). Okunol (1969) gave a rough estimation of the yearly fluctuations in the population of $L$. dimidiatus in the vicinity of Shirahama, but no confirmation was made whether there were reproducing individuals or not. Kuwamura (1976b) briefly described the seasonality in breeding and other activities of the species there.

The present paper describes the life history and the fluctuation of population in L. dimidiatus in Shirahama, and the modifications in the life history pattern near the northern limit of its range are discussed, being compared with those in southern localities.

\section{Study Areas and Methods}

The present study was carried out at the shallow submerged rocky reefs in the vicinity of the Seto Marine Biological Laboratory of Kyoto University in Shirahama, approximately $33^{\circ} 42^{\prime} \mathrm{N}$ and $135^{\circ} 20^{\prime} \mathrm{E}$ (Fig. 1), over the period of six years from October 1972 to March 1979. Observations were made underwater mainly by SCUBA diving and sometimes by snorkelling. The populations at three separated rocky reefs, i.e. Stations A, B and C (Fig. 1), were intensively studied. Each reef consists of complicatedly shaped rock beds carrying variously sized boulders, surrounded with sandy or pebbly flat bottoms. The reefs studied covered an area of $500 \mathrm{~m}^{2}, 2,200 \mathrm{~m}^{2}$ and $1,900 \mathrm{~m}^{2}$ respectively. A maximum water depth was about five meters on the offshore side of the margin of each reef. Algal vegetation mostly consisting of Undaria undarioides, Eckloniopsis radicosa and Sargassum spp. was conspicuous during spring. Colonies of corals, mostly of Acropora spp., were commonly found growing up to about $50 \mathrm{~cm}$ in diameter especially in St. B and C, but most of them were perished after the winter cold in 1976 and 1977.

Positions of individuals with their estimated total lengths and behaviours were recorded into a map of the study area, which had been painted on a roughened polyvinyl chloride plate, during about one-hour diving throughout the whole study area of each station. Observations were made usually more frequently than once per month. Supplemental observations and collections were occasionally made at rocky reefs in the vicinity other than the three stations.

To discriminate individuals, all or partial individuals in each study area were tagged. Monofilament nylon line was inserted through a puncture in the dorsal musculature, and one variously coloured and shaped piece of vinyl sheet, about 


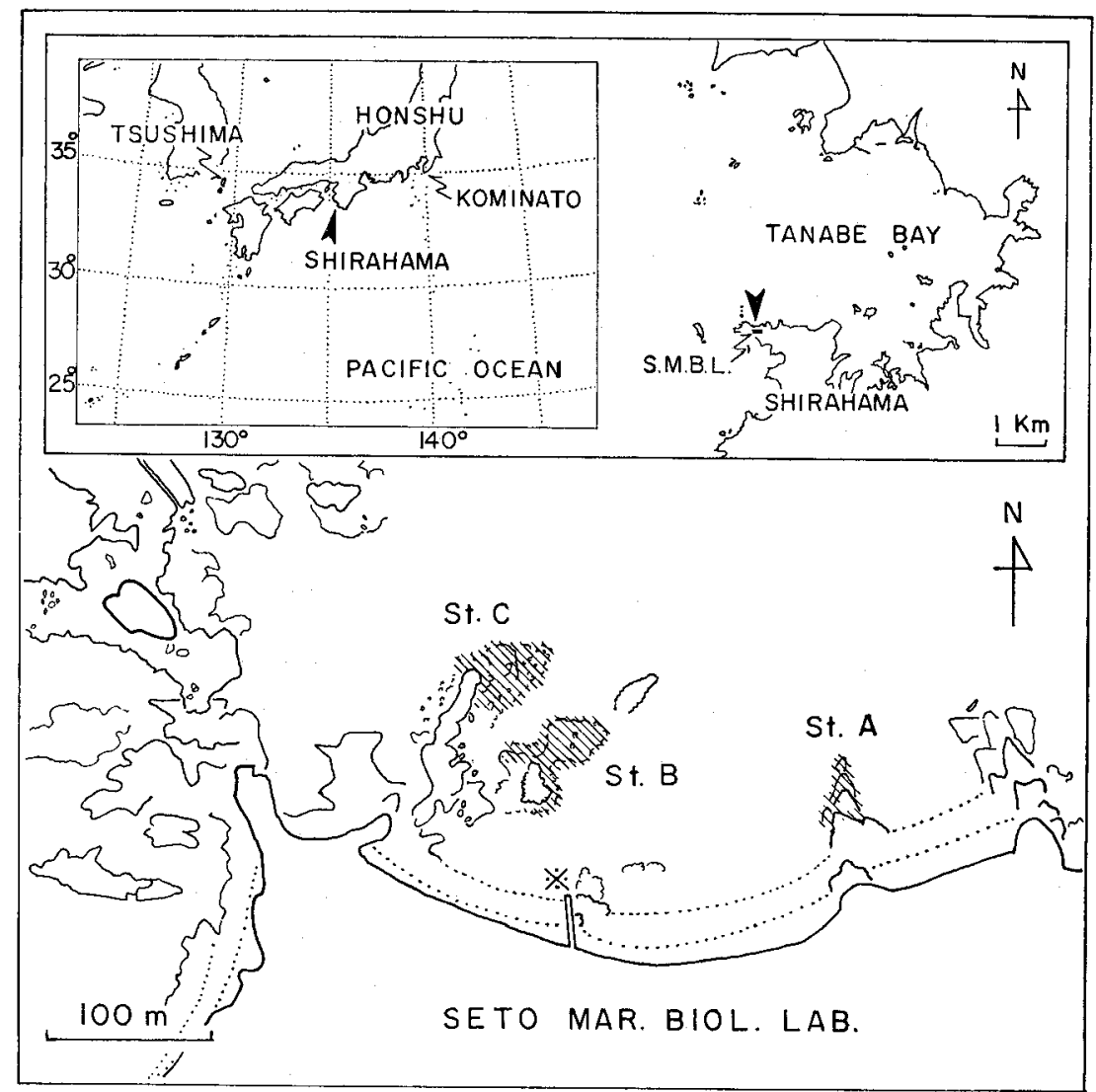

Fig. 1. Map of the study area. The northernmost localities of L. dimidiatus in the vicinity of Japan (Tsushima and Kominato) are also put in the map.

Table 1. The duration of carrying a tag.

\begin{tabular}{|c|c|c|c|c|c|}
\hline \multirow{2}{*}{ Station } & \multirow{2}{*}{ Date of tagging } & \multirow{2}{*}{$\begin{array}{l}\text { No. of tagged/ } \\
\text { inhabiting fish }\end{array}$} & \multicolumn{3}{|c|}{ Duration of carrying a tag (days) } \\
\hline & & & $\min$. & $\max$ & mean \\
\hline A & Jun. $1-3,1974$ & $7 / 7$ & 22 & 66 & 39.7 \\
\hline A & Mar. 18-20, 1975 & $10 / 10$ & 13 & 132 & 75.8 \\
\hline A & Jul. $3-24,1975$ & $7 * / 10$ & 20 & 105 & 52.0 \\
\hline \multirow{2}{*}{ A } & \multirow{2}{*}{ Sep. $17-27,1975$} & $\{3 / 7$ (adult) & 33 & 99 & 65.7 \\
\hline & & $7 / 8$ (juvenile) & 4 & 101 & 38.6 \\
\hline $\mathrm{B}$ & Jun. $15-21,1975$ & $25 * * / 25$ & 3 & 142 & 43.0 \\
\hline C & May $29-30,1977$ & $8 / 9$ & 5 & 81 & 37.3 \\
\hline
\end{tabular}

* One of these was captured by the lizard fish just after it was released.

** One of these died during tagging operation.

$5 \mathrm{~mm}$ in diameter, were secured on the line. Fishes caught by dip net or small gill net were brought into the laboratory, where, after they were put under anesthesia using MS-222 or quinaldine dilution, their total and standard lengths were measured and then they were tagged. On the next day or the day after next, they were re- 
turned to the reef where they had been caught, except five individuals which were transferred to a reef far away from their native reef. Table 1 shows the number of individuals tagged in each reef and the period of keeping a tag. The tag was usually carried for one or two months. The longest period of carrying a tag, so long as eight months, was exhibited by one of the transferred fish which were not shown in Table 1. Growth of filamentous algae on a tag often made it difficult to discriminate the colour of the tag, in one month or so after tagging. Even on such occasions, however, not a few individuals could be discriminated by their body size and colour, and so was the case for the fish that lost the tag. Each station was intensively investigated more frequently than once in every two days for one or two months after tagging.

\section{Colour Variation and Ontogenical Coloux Change}

Two main colour variants have been known in $L$. dimidiatus: the dimidiatus form and the paradiseus form. Although L. paradiseus Bleeker (1851) differs from dimidiatus in having a hooklike ventroanterior extension of the broad black band in the caudal fin, it is regarded as a colour variety since there are intermediates between typical dimidiatus and the paradiseus form (Randall, 1958). A black bar at the pectoral fin base also appears to be a characteristic of the paradiseus form (Springer and SmithVaniz, 1972; Robertson, 1974). It is known that juveniles lack the black bar on the pectoral fin base, while adults always have it in the Red Sea specimens (Springer and Smith-Vaniz, 1972), and that the ventrally curving hook in the caudal fin also develops late in adult life in the Aldabra form (Potts, 1973).

Fifty-six specimens collected from Shirahama were examined for their colour patterns. The colour change with growth is described below with special reference to the formation of the "hook" in the caudal fin and the black bar at the pectoral fin base (Table 2).

Juvenile stage $(10-50 \mathrm{~mm}$ in total length; Fig. 2B): The body of the smallest

Table 2. Ontogenic change and variations in the colour pattern of L. dimidiatus.

The number of specimens showing each pattern is given.

\begin{tabular}{|c|c|c|c|c|c|c|c|c|c|c|}
\hline $\begin{array}{l}\text { Total } \\
\text { length } \\
(\mathrm{mm})\end{array}$ & $\begin{array}{l}\text { No. of } \\
\text { specimens } \\
\text { examined }\end{array}$ & $\begin{array}{l}\text { Indis- } \\
\text { cernible }\end{array}$ & the pect & 1 fin base & $\begin{array}{l}\text { Indis - } \\
\text { cernible }\end{array}$ & Receding & ok in th & audal Si & $\begin{array}{l}\text { Alinost } \\
\text { joined }\end{array}$ & $\begin{array}{l}\text { Well } \\
\text { developed }\end{array}$ \\
\hline $10-50$ & 13 & 13 & 0 & 0 & 13 & 0 & 0 & 0 & 0 & 0 \\
\hline $50-60$ & 12 & 0 & 1 & 11 & 2 & 3 & 2 & 3 & 1 & 1 . \\
\hline $60-70$ & 16 & 0 & 0 & 16 & 0 & 0 & 1 & 1 & 8 & 6 \\
\hline $70 \cdot 80$ & 9 & 0 & I & 8 & 0 & 0 & 0 & 0 & 3 & 6 \\
\hline $80-90$ & 5 & 0 & 0 & 5 & 0 & 0 & 0 & 0 & 1 & 4 \\
\hline $90-100$ & 1 & 0 & 1 & 0 & 0 & 0 & 0 & 0 & 0 & 1 \\
\hline TotaI & 56 & 13 & 3 & 40 & 15 & 3 & 3 & 4 & 15 & 18 \\
\hline
\end{tabular}


juveniles is almost completely black except for a deep blue band beginning at upper lip and extending backward along the dorsal region, where it gradually narrows until it terminates dorsally on caudal peduncle. As the fish grow, the pale region in the thorax expands along the ventral side. The dorsal blue band also increases in width ventrally, extending posteriorly to the edge of caudal fin. In this stage no hook or bar is distinguishable from the dark ground colour in the caudal fin or at the pectoral fin base, respectively (Table 2 ).

Transitional stage (50-60 $\mathrm{mm}$ in total length): With the expansion of the pale blue area along the ventral side and the dorsal blue bar, which gradually loses the brilliance of the blue colour, there is a gradual development of the longitudinal black stripe of the adult. In the region just below the pectoral fin base the receding black area of the body surface leaves a black spot or bar, measuring $0.9-2.0 \mathrm{~mm}$ in the major axis, in a whitish area. Only one specimen of twelve lacked this black bar (Table 2). In the caudal fin region the specimens exhibited various degrees of colour pattern from entirely black to developing a hook (Table 2). The receding black area often leaves a narrow broken dark stripe beginning at the posterior end of the black base of the anal fin and terminating in the middle of the caudal fin on the lower edge of the median black band, but afterwards the region below the median black band in the caudal fin becomes entirely pale blue, making a simple broad wedge in the tail region just as in the dimidiatus form. A black hook subsequently develops, extending from the posterior end of the black base of the anal fin towards the lower posterior end of the median black band. One specimen, $59.2 \mathrm{~mm}$ in total length, had a well developed hook, although the hook was narrower than that of adults.

Adult stage (60-110 mm in total length; Fig. 2A): As maturity is reached at the size of about $60 \mathrm{~mm}$ in total length, individuals larger than the length may be reasonably called adult. Adults are pale straw yellow anteriorly and pale blue posteriorly with a longitudinal black body stripe extending through the eye to the tail, the width of which decreases with growth. The brightness of the yellow and blue colour in the body differed largely between specimens. Twenty-nine out of 31 specimens had a black bar, measuring $1.3-3.7 \mathrm{~mm}$ in the major axis, just below the pectoral fin base. All of the larger adults have an almost completely developed ventroanterior hook in the caudal fin (Table 2). No sexual dichromatism was

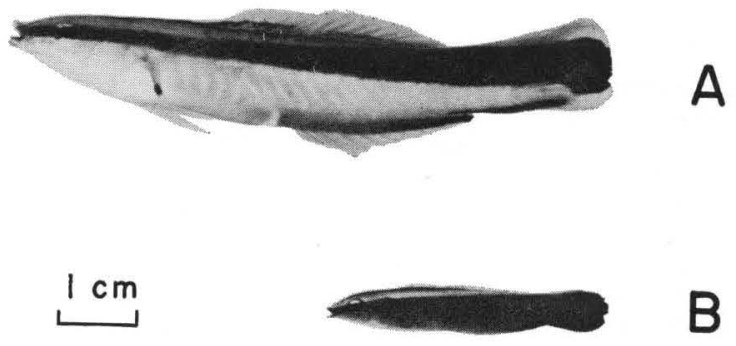

Fig. 2. Adult (A) and juvenile (B) of Labroides dimidiatus. 
noticed except that the male has an older colour pattern than the female, as protogynous sex-change takes place in $L$. dimidiatus.

The Shirahama form is decisively regarded as the paradiseus variant, for all the larger specimens had a well developed black hook in the caudal fin, although a few of them lacked the black bar at the pectoral fin base.

\section{Fluctuation in Abundance}

L. dimidiatus in Shirahama commonly occurs on the inshore rocky reefs, whereas it does not live on the sand or pebble areas. Fluctuations in the size of population at three study areas are given in Fig. 3. The populations increased in summer and autumn, but decreased in winter, sometimes nearly to zero. A small increase observed in spring seems a deceptive appearance, for in winter even surviving individuals become so inactive and apt to hide themselves in rock crevices (see the next section for detail) that some of them may have escaped from the observer.

The increase in summer and autumn is caused by the recruitment of juveniles. Settlement of juveniles began as early as late June in St. A and July in St. B in 1975, and as late as September in all stations in 1976 and 1977. Settlement usually lasted for two to three months, but in a few cases it occurred still in January. The numbers

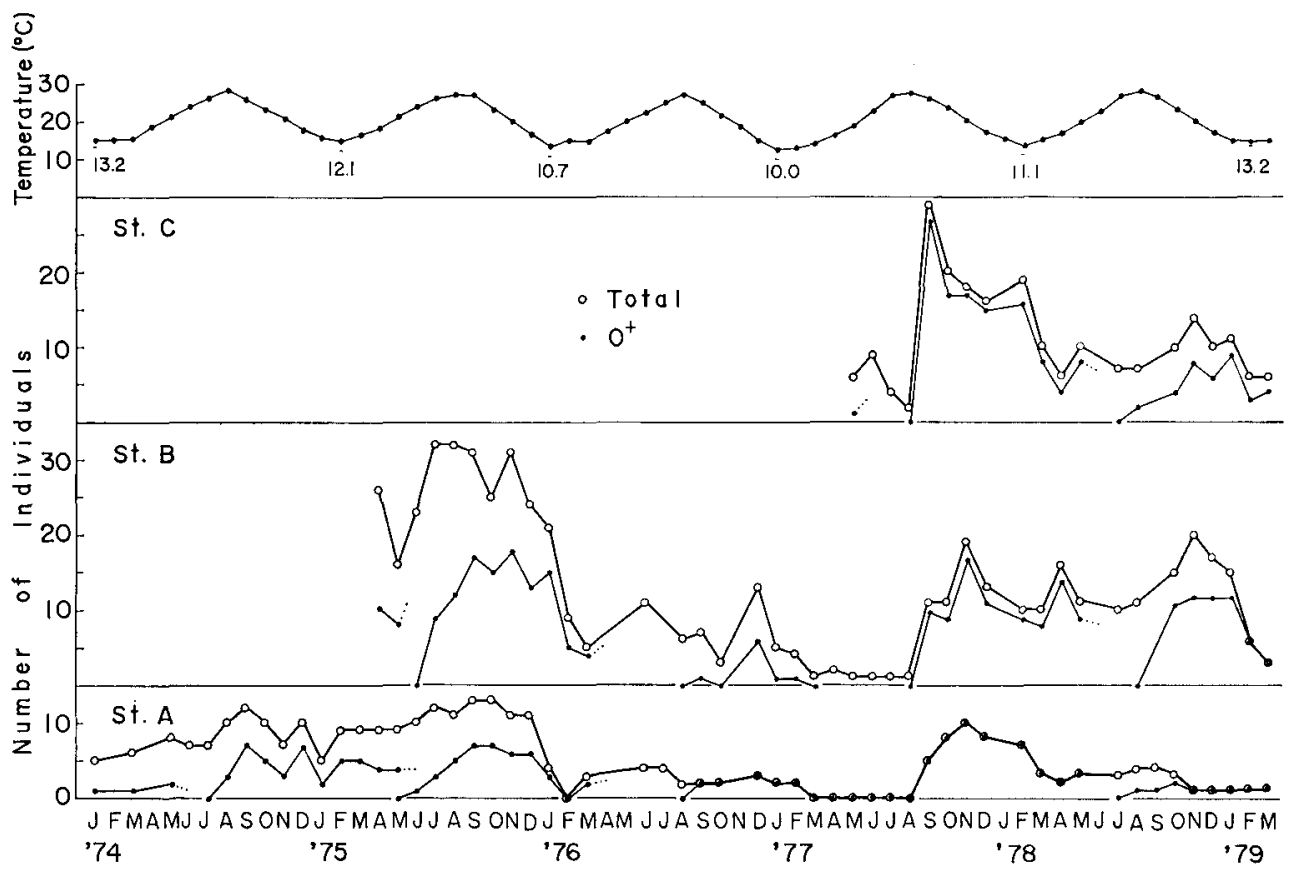

Fig. 3. Monthly fluctuation of the number of individuals in each station. The maximum numbeis observed in each month are given. Under-yearlings are distinguished since recruitment until next May. Monthly averages of the surface water temperatures measured at the pier of the laboratory (Fig. 1\%) at 9:00 everyday are also shown, accompanied with the lowest temperatures in winter. 
Table 3. Densities before and after recruitment. Densities per $100 \mathrm{~m}^{2}$ are shown. Summer: before recruitment; Autumn: after recruitment; A: adult; J: juvenile; $\mathrm{T}$ : total.

\begin{tabular}{|c|c|c|c|c|c|c|c|c|c|c|c|c|}
\hline \multirow{3}{*}{ Years } & \multicolumn{4}{|c|}{ St. A } & \multicolumn{4}{|c|}{ St B } & \multicolumn{4}{|c|}{ St. G } \\
\hline & \multirow{2}{*}{$\frac{\text { Summer }}{\mathrm{A}=\mathrm{T}}$} & \multicolumn{3}{|c|}{ Autumn } & \multirow{2}{*}{$\frac{\overline{\text { Summer }}}{\mathrm{A}=\mathrm{T}}$} & \multicolumn{3}{|c|}{ Autumn } & \multirow{2}{*}{$\frac{\text { Summer }}{A=T}$} & \multicolumn{3}{|c|}{ Autumn } \\
\hline & & $\mathrm{A}$ & $\mathrm{J}$ & $T$ & & $\mathrm{~A}$ & $\mathrm{~J}$ & $\mathrm{~T}$ & & $\mathrm{~A}$ & $\mathrm{~J}$ & $\mathbf{T}$ \\
\hline 1973 & 2.2 & 1.4 & 0.6 & 2.0 & - & - & - & - & - & - & - & - \\
\hline 1974 & 1.4 & 1.0 & 1.4 & 2.4 & - & - & - & - & - & - & - & 一 \\
\hline 1975 & 1.8 & 1.2 & 1.4 & 2.6 & 1.1 & 0.6 & 0.8 & 1.4 & - & 一 & 一 & - \\
\hline 1976 & 0.8 & 0 & 0.6 & 0.6 & 0.5 & 0.3 & 0.3 & 0.6 & - & 一 & - & - \\
\hline 1977 & 0 & 0 & 2.0 & 2.0 & 0.1 & 0.1 & 0.8 & 0.9 & 0.5 & 0.2 & 1.4 & 1.6 \\
\hline 1978 & 0.6 & 0.2 & 0.4 & 0.6 & 0.5 & 0.4 & 0.5 & 0.9 & 0.4 & 0.3 & 0.4 & 0.7 \\
\hline
\end{tabular}

of juveniles recruited varied considerably year to year (Fig. 3 and Table 3). No special correlationship is found between densities of juveniles in autumn and densities of adults in summer or autumn. The success of juvenile recruitment after extended pelagic life of eggs and larvae may be much affected particularly by the condition of the sea current, which transports eggs and larvae, but nothing is known about the distribution and transport of eggs and larvae of $L$. dimidiatus in the vicinity of Shirahama.

Though the adult populations were rather stable during spring to early summer, they exhibited gradual decrease in late summer and autumn, that is, before or at the beginning of the juvenile recruitment (Fig. 3 and Table 3). As no tagged individual was observed emigrating from one reef to another, the decrease of population is probably attributed to death. The death may be related partly to ground swells caused by typhoons, which frequently hit the vicinity of Japan at that season of the year.

In winter, decrease in abundance occurred both in adults and juveniles. The decrease is probably due to low water temperature: it drops to as low as $10^{\circ} \mathrm{C}$, monthly averages of temperatures ranging from $12^{\circ} \mathrm{C}$ to $16^{\circ} \mathrm{C}$ in winter months. In cold winters of 1976 and 1977, many fishes were stranded on the beach near the laboratory, as was observed in 1968 and other years (Araga and Tanase, 1968), and L. dimidiatus was also found among them.

\section{Activity and Social Organization}

Diurnal and Seasonal Changes in Activity

$L$. dimidiatus is active in the daytime, and rests at night in crevices or holes in rocks. Adults usually left their holes several minutes after sunrise, and returned to them several minutes before sunset. Juveniles left their holes slightly earlier than adults, and returned to them slightly later. In both adults and juveniles feeding behaviour, which is cleaning other fishes in most cases (Kuwamura, 1976b, 1980a), can be seen at anytime of the day.

In winter, and occasionally in other seasons, some individuals were hiding themselves in crevices even in the daytime. Seasonal fluctuation of the activity rate, 
which is defined as the ratio of the number of individuals observed in each survey to the whole number of individuals confirmed to inhabit the study area, is shown in Fig. 4. Almost all individuals are always active during late spring and early summer, but the activity rate declines slightly from late summer, and decreases remarkably in winter especially in adults. In spring, under-yearlings become active earlier than adults. The low activity in winter appears to be due to the low water temperature, and the increase of the activity in spring is seemingly associated with the increase of the water temperature which rises over $20^{\circ} \mathrm{C}$ in late April. In summer and autumn the low activity was observed when the sea was rough.

Seasonal Change of Home Range

The home range of an individual is determined by enclosing all the observed positions of it. The seasonal changes of the home ranges of all the individuals at St. A in 1975 are given in Fig. 5 and Fig. 6. As the frequencies of the survey in each month varied remarkably (Fig, 4), the home range can not be compared to its details in size or shape. However, the stability or the mobility of the position of the home range can be outlined.

In March there were 10 individuals in the study area, and five of those ( F4, F5, F6, F7 and F8) were seemingly under-yearlings, and the rest were older than one year. At that time most of individuals were still less active and restricted their range within a smaller area than in summer. The positions of home ranges of two males (M1 and M2) and the larger females (F1, F3, F4 and F5) were stable from March to December. A large female F2 changed its range to the south part in early May, and since then its range was rather stable. Home ranges of the smaller females

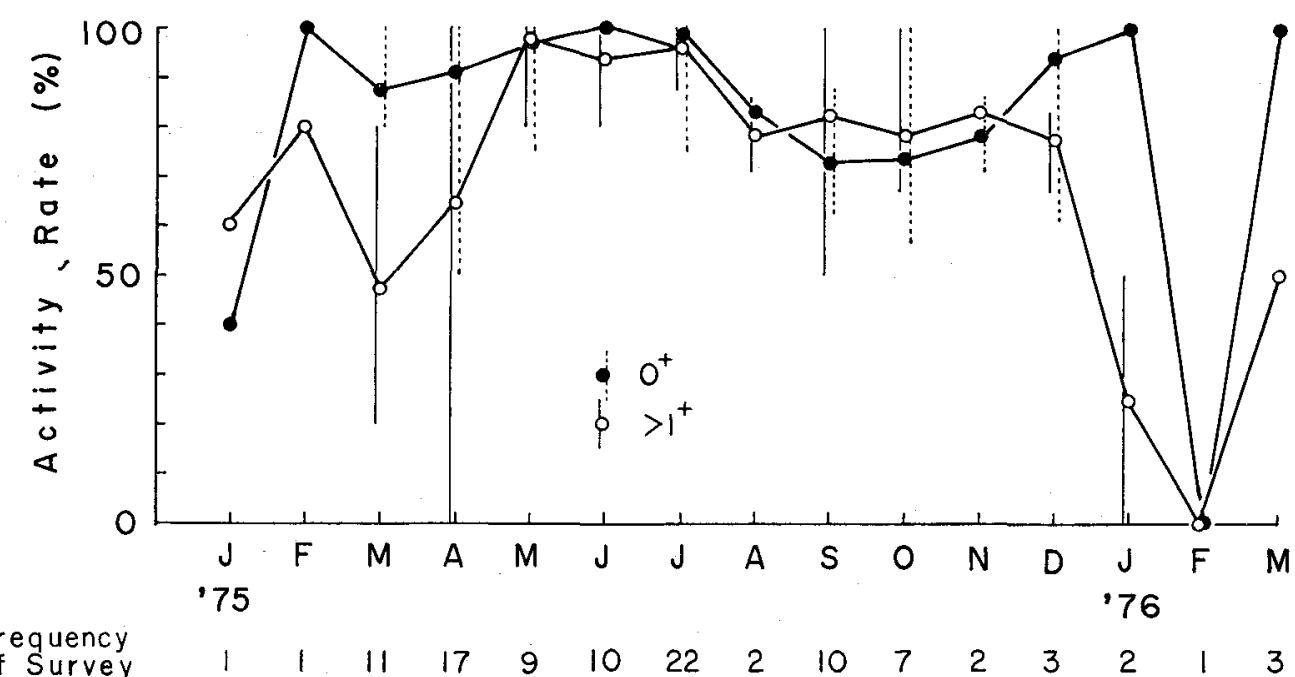

Fig. 4. Seasonal change of activity at St. A. The ratio of the number of individuals observed in each survey to the whole number of individuals confirmed to inhabit the study area is used as the activity rate. The monthly averages with maximum and minimum ranges are shown for under-yearlings and adults $\left(>1^{+}\right.$old $)$respectively. 
$' 75$

MAR APR MAY JUN JUL AUG SEP OCT NOV DEC

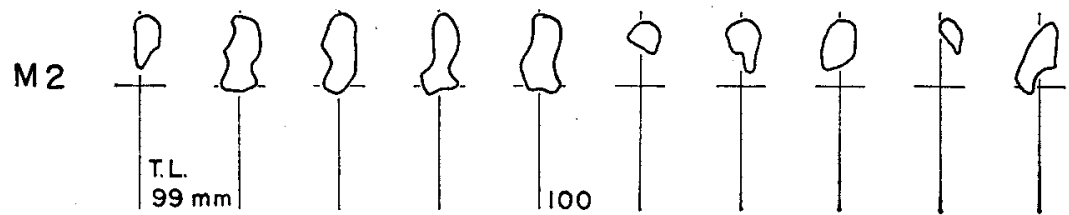

$\left.\right|_{81} ^{\infty} \sum_{\sqrt{n}}^{\infty} \frac{1}{\sqrt{n}}$

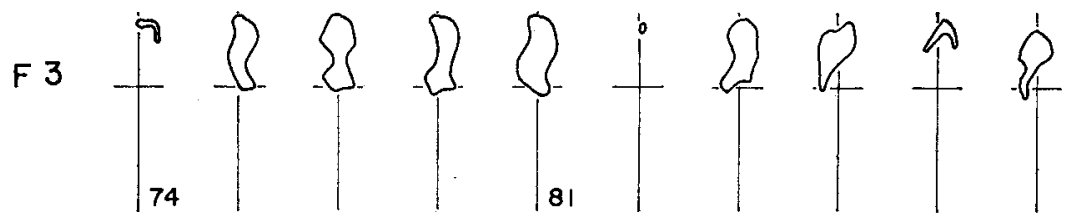

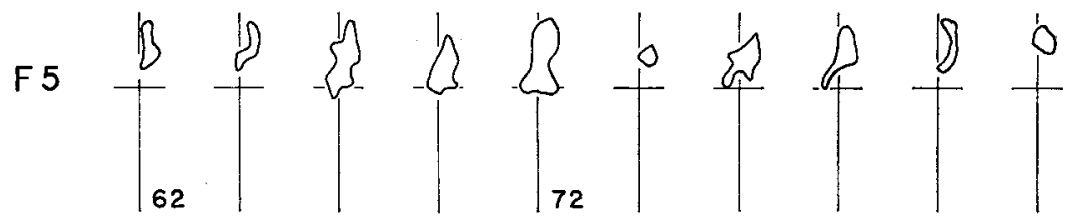

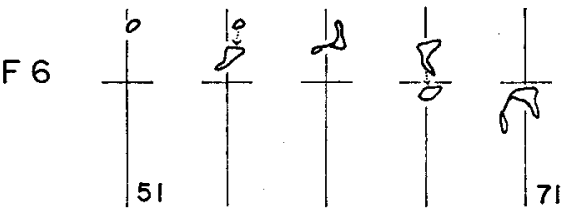

F 8 |

Fig. 5-1

(F6 and F8) were more mobile than the larger. Two females (Fa and Fb) were artificially transferred to the study area from other reefs in July, and the smaller one $(\mathrm{Fb})$ also changed considerably its home range thenceforth.

Juveniles usually live within an area of $1-2 \mathrm{~m}$ in diameter for about one month after settlement, and then they become mobile and begin to enlarge their home ranges. The greatest shift of home range was exhibited by J8, which changed its 
MAR APR MAY JUN JUL AUG SEP OCT NOV DEC

M I

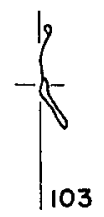<smiles>COc1ccccc1</smiles><smiles>CC1CC2CCCC(C1)C2</smiles><smiles>CC1CCCC(C)C1</smiles>
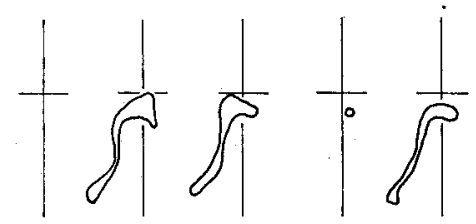

F I<smiles>CPCC(C)C</smiles><smiles>Cc1ccccc1C</smiles><smiles>Cc1ccccc1</smiles><smiles>CSC1(C)N=C=C1Br</smiles>

F4
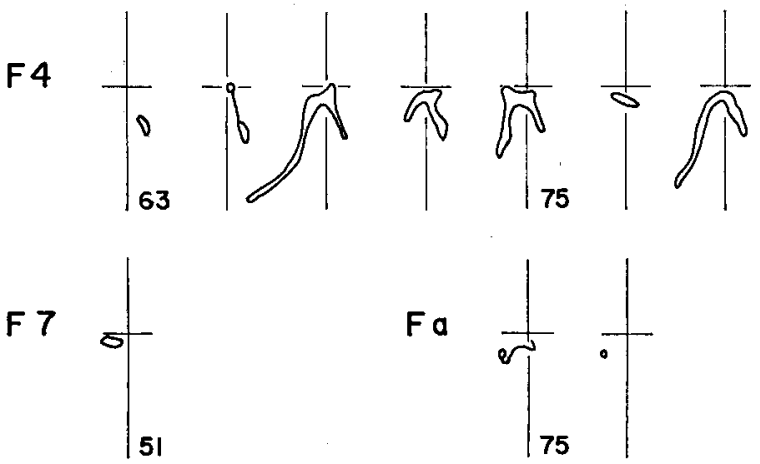

$F a$
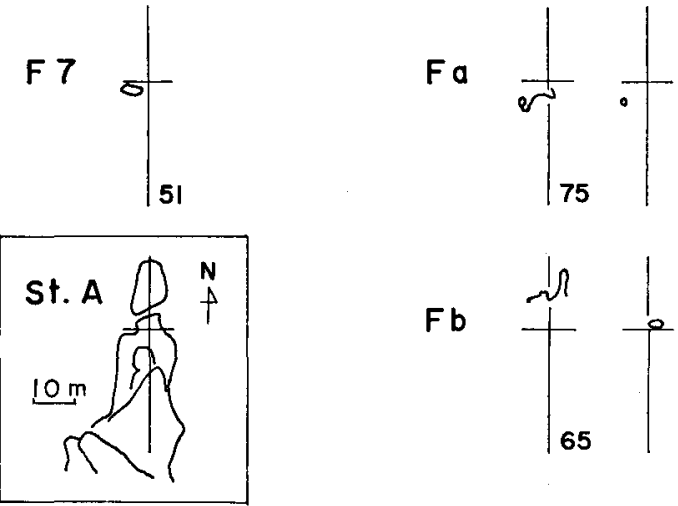

F b
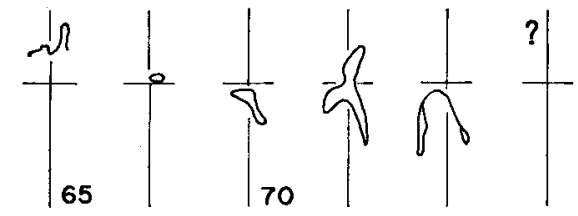

Fig. 5-2

Fig. 5. Seasonal change of the position of home range in adults at St. A. A question mark is put when individual discrimination could not be made exactly. The frequency of surveys in each month is the same as in Fig. 4.

range from the southern end of the study area to the northern end of it during September to November. The largest home ranges of juveniles in October almost caught up in size with those of smaller adults.

During winter of 1976 only one male (probably M2) and one female were observed, and the rest of adults did not appear again even in spring or summer of the year. Although juveniles were observed more frequently than adults in winter, they also restricted their ranges within a smaller area than in autumn.

\section{Range Overlap and Social Organization}

The two males (M1 and M2) held their ranges dividing the whole study area, 


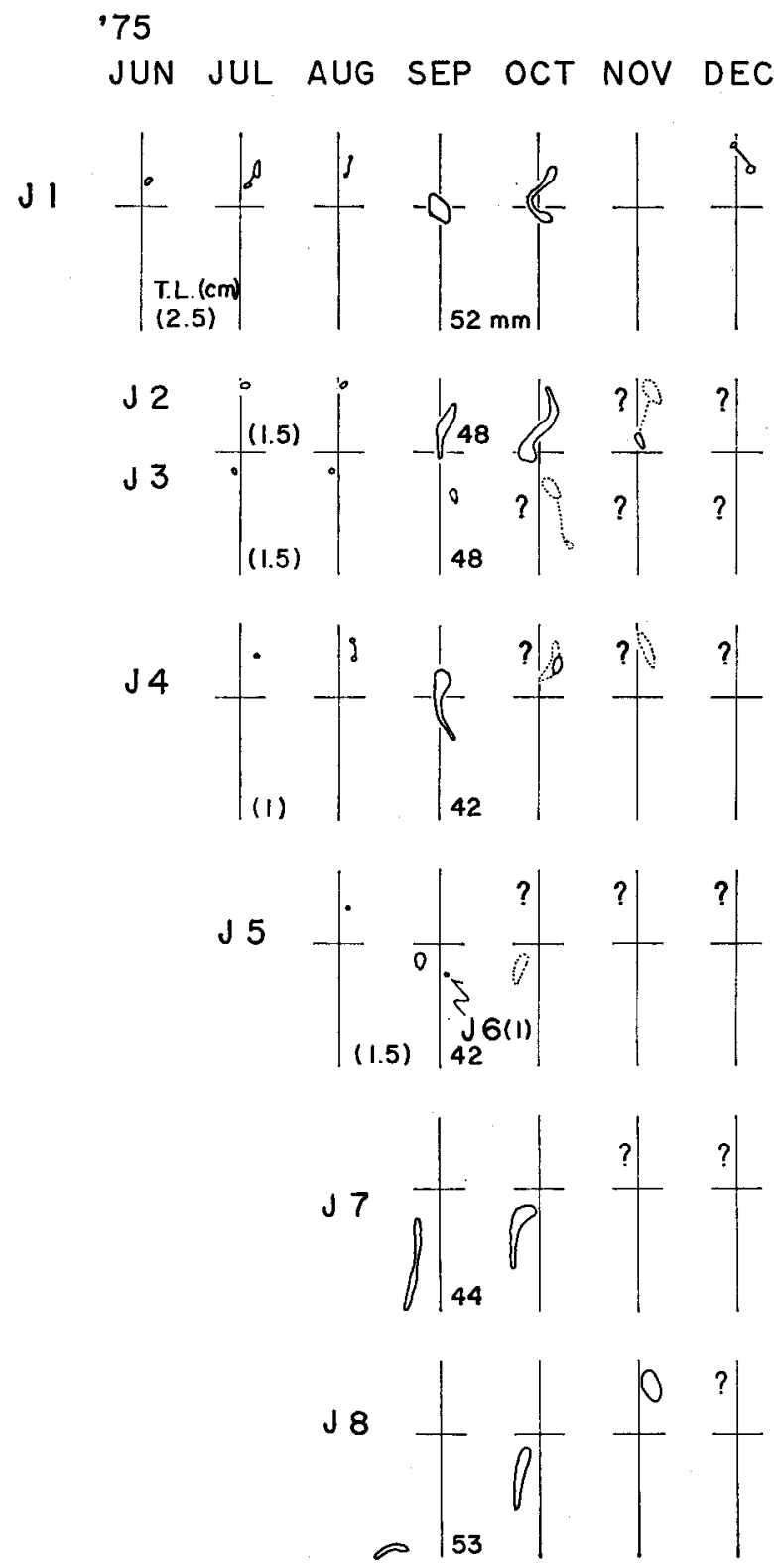

Fig. 6. Seasonal change of the position of home range in juveniles at St. A.

in the northern part and southern part respectively, during April to December. In winter of 1975 both were sometimes observed in the northern part, and Ml was still found intruding the northern part frequently in March and once in early April. Territorial border fights were observed between the two from late April, and thenceforward till December, no mutual intrusion was observed except for on July 10 when M2 was absent as it had been collected the day before for re-tagging. 
Females usually restricted their home range within the territory of each male. In autumn, however, some of the smaller females (F8 and Fb) extended their home ranges beyond the boundary between the two males. Juveniles more often crossed the territory border between the males, with enlargement of their home range.

Within a male's territory, home ranges of females largely overlapped each other, and especially in larger females their ranges were almost superimposed on the territory of their male. All juveniles settled within the home ranges of adults, and they also overlapped their range each other, with enlargement of range. Among individuals within a male's territory, a linear "peck-right" type dominance hierarchy was observed in their aggressive encounters. The dominance hierarchy was mostly size-based, and the male always at its top. Mating was restricted between a male and females living within the male's territory.

When a male (M2) was removed from its territory on July 9, the largest female (F3) within the male's territory began to exhibit male displays against other females about one hour after removal of the male. Although F3 did not become a functional male, as M1 was returned to the study area on the next day, the observation suggests that the male controls sex-change in females within its territory. Another case also indicates the occurrence of sex-change in natural condition: an individual, which was the largest female in a male's territory at St. B till July in 1975, was later observed exhibiting male displays at the peripheral area of the male's territory.

To sum up, a social group comprising a male and a harem of several females within the male's territory, as has been observed at Heron Island and Aldabra Island by Robertson (1972, 1974; Robertson and Choat, 1974; Robertson and Hoffman, 1977), was also found in Shirahama. The social grouping, however, was apparent only from A pril to December, for in winter, social encounters occurred less frequently and no territorial defence was observed between males. Territory border of males was more frequently crossed by smaller individuals rather than larger ones, and in autumn rather than in spring and summer.

\section{Reproduction and Early Development}

Spawning System and Spawning Period

Spawning in L. dimidiatus always included a pair of a male and a female living within the male's territory. After the sequence of courtship displays continued in more or less time, the pair rushed upward a few meters off the bottom where eggs and sperm were released free into the water. Spawning occurred mostly at the offshore fringe of the reef in a male's territory.

The time of spawning and pseudospawning (no release of eggs: Robertson, 1974) was mostly restricted to the period of two hours around noon, and was not correlated with the tidal cycle (Fig. 7). Within the reproductive time, more than two females were often observed mating successively with their male.

Spawning was confirmed to occur within 4-5 months of the year, from late May to early September. Females with egg-swollen abdomen were also observed 


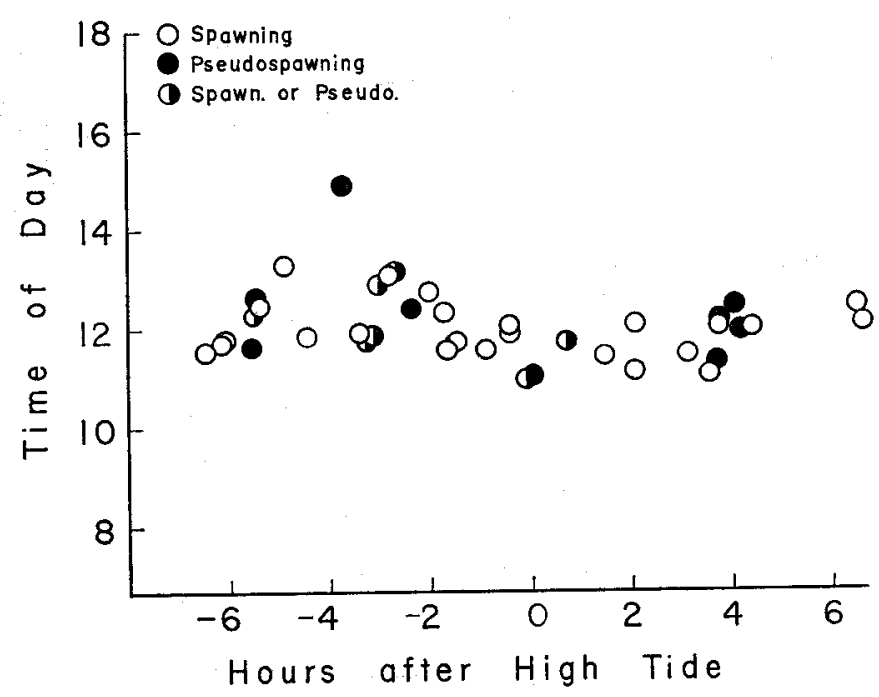

Fig. 7. Diurnal timing of sexual activity.

restrictedly in the period from May to September. However, pseudospawning occurred in the longer period from April to November, and even in late March courtship and prespawning behaviours were observed in a few cases. No correlation was found between the occurrence of spawning and the phases of the moon, and spawning probably occurred almost everyday.

Egg and Larva

The eggs, which were released at the peak of the spawning rush and were momentarily visible as a pale cloud, were scooped with a vinyl bag $(30 \times 50 \mathrm{~cm})$ on June 15, 1974 (spawning at 12:20), June 28, 1974 (spawning at $11: 45$ ) and July 5, 1975 (spawning at 13:05). They were kept in a 30 liter tank with weak aeration, and early development was observed. During the observations, the water temperature in the rearing tank ranged from 21.3 to $27.0^{\circ} \mathrm{C}$.

Eggs are buoyant, colourless and spherical, $0.66-0.69 \mathrm{~mm}$ in diameter, containing numerous oil globules which will join together afterwards. The egg membrane is smooth, without any conspicuous structure, the yolk not segmented and the perivitelline space narrow.

In 3 hours and a half after spawning, the eggs reach the morula stage. Dozens of, up to one hundred, oil globules, very small to as large as $0.10 \mathrm{~mm}$ in diameter, remain in aggregation (Fig. $8 \mathrm{~A}$ ).

In 8 hours and a half after spawning, the eggs reach the blastula stage, containing one oil globule, $0.13-0.14 \mathrm{~mm}$ in diameter. A few eggs still have another very small oil globule, $0.02 \mathrm{~mm}$ in diameter, beside the larger (Fig. 8B).

At 11 hours after spawning, the formation of the embryo is commenced. An oil globule, $0.14-0.17 \mathrm{~mm}$ in diameter, is situated on the opposite side of the embryo (Fig. 8C). 

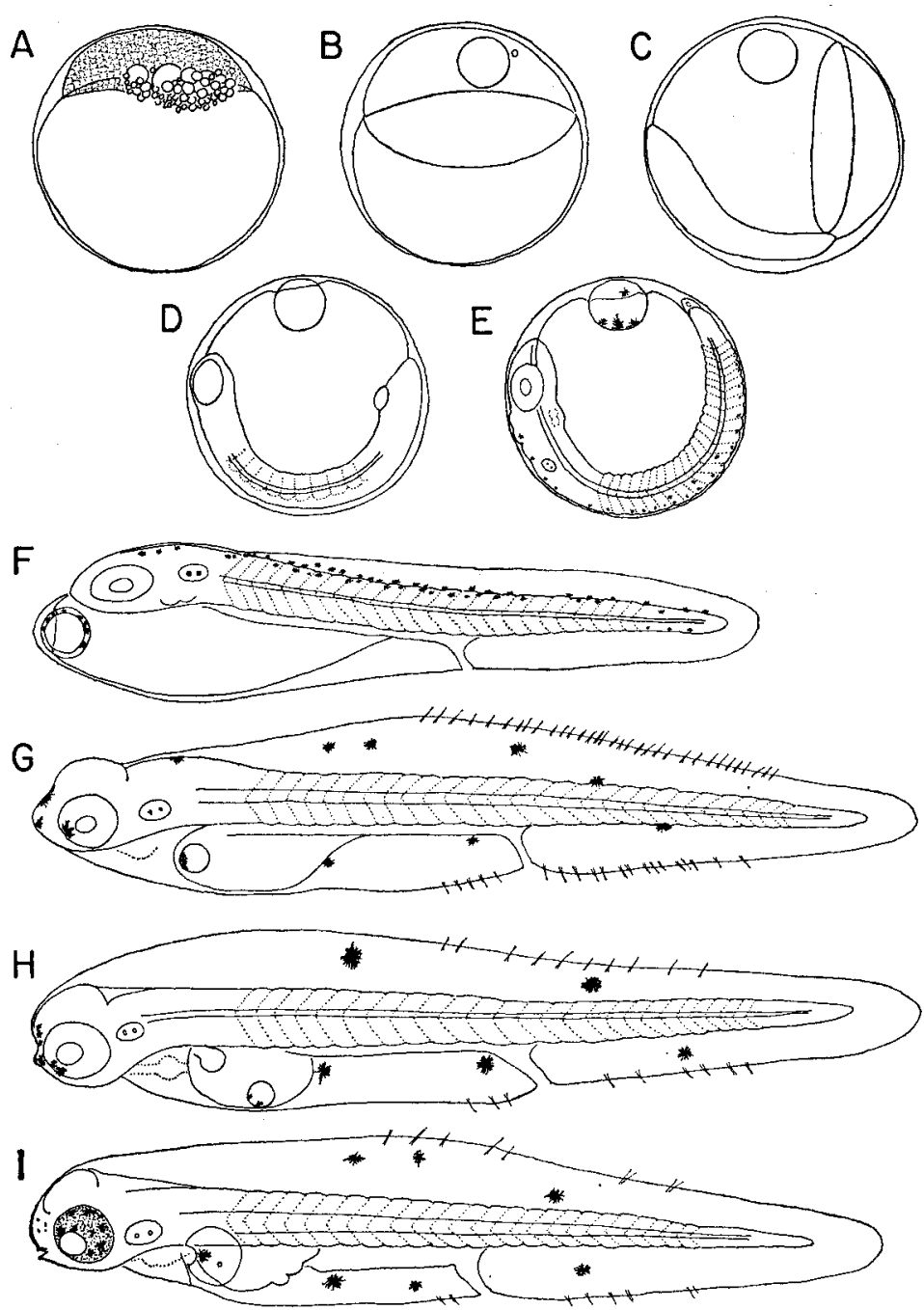

Fig. 8. Development of egg and larva of $L$. dimidiatus.

A: Morula stage, $3.5 \mathrm{hrs}$. after spawning, $0.67 \mathrm{~mm}$ in diameter. B: Blastula stage, $8.5 \mathrm{hrs}$. after. C: Formation of embryo, 11 hrs. after. D: 9-myotome stage, 13.5 hrs. after. E: 24-myotome stage, $21 \mathrm{hrs}$. after. F: Larva just hatched, $1.78 \mathrm{~mm}$ in total length. G: Larva 15 hrs. after hatching, $2.30 \mathrm{~mm}$ in total length. $\mathrm{H}$ : Larva 1 day old, $2.31 \mathrm{~mm}$ in total length. I: Larva 2 day old, $2.20 \mathrm{~mm}$ in total length.

At 13 hours and a half after spawning, the blastopore is closed and nine myotomes have been differentiated. The optic vesicles and the Kupffer's vesicle also appear. A part of the oil globule projects out of the yolk sac (Fig. 8D).

At 21 hours after spawning, the embryo have 24 myotomes, and the lens, the ear vesicles and the heart are visible. The Kupffer's vesicle disappears. About 30 melanophores appears on the body as well as on the oil globule (Fig. 8E).

Hatching takes place in 29-30 hours after spawning and falls at the time of sunset as spawning occurs around noon of the day before. 
The newly hatched larvae have an ovoid yolk sac which is usually protruding anteriorly beyond the head, and the oil globule is situated in the anterior part of the yolk. The total length is ranging from 1.78 to $1.81 \mathrm{~mm}$, the length from the anterior end of the yolk sac to the end of the tail measuring $1.88-1.91 \mathrm{~mm}$. The anus opens at about two-thirds of the longitudinal body. On the dorsal median line of the body 20 to 60 melanophores are arranged in one or two rows. Melanophores are also seen on the oil globule. The number of myotomes is $14+10=24$ (Fig. 8F). The newly hatched larvae float with the yolk sac upward, just below the surface of the water in the rearing tank.

The larvae 15 hours after hatching, measuring $2.00-2.30 \mathrm{~mm}$ in total length, have $13+14=27$ myotomes. The yolk has visibly decreased in amount, the anterior end of it receding posteriorly below the ear. The serration with about 50 teeth appears on the fringe of the marginal fin. Melanophores decrease to 10-12 in number, being distributed on the dorsal and ventral marginal fins, as well as on the head, the eyes and the oil globule (Fig. 8G).

On one day after hatching, the larvae are $2.31-2.56 \mathrm{~mm}$ in total length, having $12+13=25$ myotomes. The pectoral fins begin to appear. The number of teeth of the serration decreases to about 20. The number of melanophores is almost unchanged or decreases a little, and the number and location of them somewhat vary among individuals (Fig. $8 \mathrm{H}$ ).

The larvae two days after hatching, measuring $2.20-2.50 \mathrm{~mm}$ in total length, have $12+12=24$ myotomes. The eyes become darker, the mouth begins to open, and the pectoral fins become extended. The oil globule and the yolk are almost absorbed. There are usually three melanophores on the ventral marginal fin, two to three on the dorsal marginal fin and a few others are located on the head, on the tail or on the anterior part of the gut (Fig. 8I). The larvae float with the head downward and the back and the tail upward in the middle depths of the tank.

In 3-6 days after hatching, the larvae measure $2.52-2.60 \mathrm{~mm}$ in total length, the pectoral fins being extended and the lower jaw visibly developping. The number and the location of melanophores are rather stable; two on the dorsal marginal fin and two to three on the ventral marginal fin. The serration is still observed. The larvae float in the normal position with the back upward in the middle depths of the tank.

The larvae were provided with Brachionus plicatilis as food, but they died in 3-6 days after hatching probably from starvation, for the gut was empty in all larvae.

Mito (1962) described the development of eggs and hatched larvae of 23 species belonging to the suborder Labroidei from Japanese waters. The egg and larva of L. dimidiatus in the present study have many common characters with those of other labrid fishes described by Mito, but the egg of the present species differs from others in having many oil globules, which join together afterwards, while the eggs of other labrids have only one oil globule throughout the development. The presence of many oil globules has also been noted in the egg of $L$. dimidiatus spawned in aquarium (Hioki, 1979). 
Eggs and larvae of $L$. dimidiatus are evidently planktonic, as they floated in the upper or middle depths of the rearing tank.

\section{Growth and Maturity}

The smallest juveniles of $L$. dimidiatus observed during the present study were about $1 \mathrm{~cm}$ in total length. Juveniles probably settle at this size. Size increases after settlement in 41 individuals are shown in Fig. 9. Those of juveniles are mostly based on the estimated total lengths in $0.5 \mathrm{~cm}$ units by field observation, while almost all of adults are based on the actual measurements in milimeters at the time of tagging.

During summer and autumn juveniles grew very rapidly from $1-2 \mathrm{~cm}$ in total length at settlement to $5 \mathrm{~cm}$, and then the growth was lowered. In December their lengths measured $5.2 \mathrm{~cm}$ in average, ranging from 2.5 to $6.5 \mathrm{~cm}(\mathrm{n}=86)$. The largest individuals exhibited the adult colour pattern. Although one individual which settled late in autumn grew rapidly continually in winter up to $5 \mathrm{~cm}$ (Fig. 9), the under-yearlings almost stopped growing during winter, and the average length in March was $5.4 \mathrm{~cm}$, ranging from 4 to $6.5 \mathrm{~cm}(\mathrm{n}=36)$. They again started to grow rather rapidly in spring, and attained the length of $6.7 \mathrm{~cm}$ in average ranging from 5 to $7.5 \mathrm{~cm}(n=15)$ in July, about one year after its birth. Adults grew more slowly, as they grew older. The growth of adults was seemingly hindered during winter, as well as that of juveniles (Fig. 9). The largest individual collected was $103 \mathrm{~mm}$ in total length, $85 \mathrm{~mm}$ in standard length, which lived more than one year after meas-

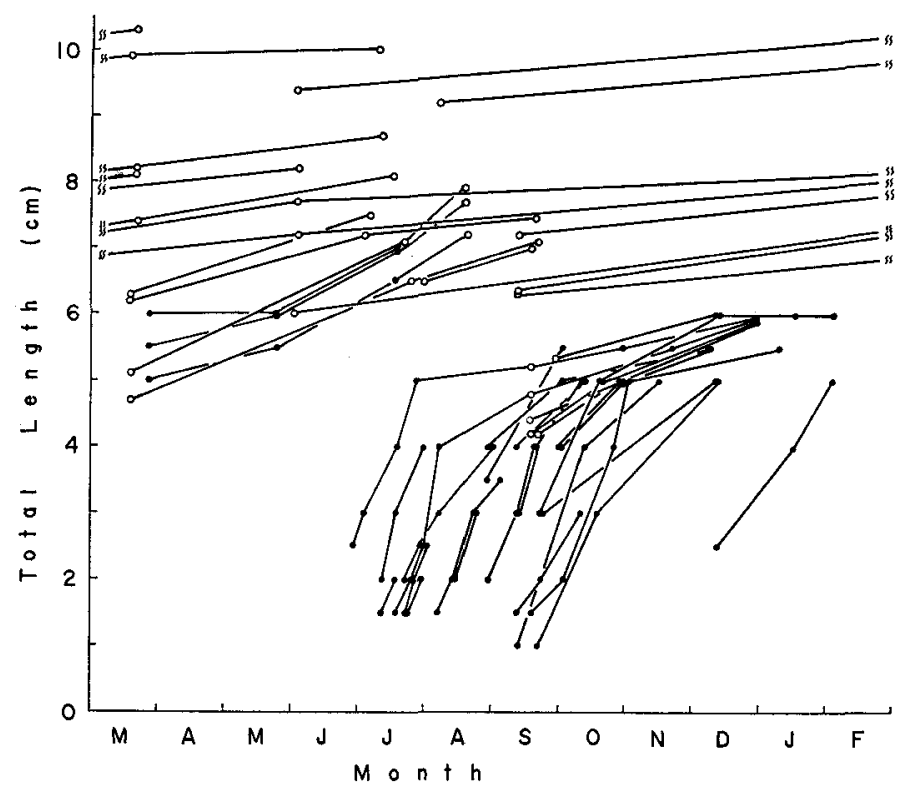

Fig. 9. Individual growths, based on the estimated total lengths in $0.5 \mathrm{~cm}$ units by field observation (solid circle) or the actual length measured on tagging (hollow circle). 
Table 4. Rate of increase in total length, calculated from the measurements shown in Fig. 9.

\begin{tabular}{cccc}
\hline $\begin{array}{c}\text { Increase in total } \\
\text { length }(\mathrm{mm})\end{array}$ & $\begin{array}{c}\text { No. of } \\
\text { samples }\end{array}$ & $\begin{array}{c}\text { Mean time taken } \\
\text { (month) }\end{array}$ & $\begin{array}{c}\text { Cumulative time } \\
\text { (month) }\end{array}$ \\
\hline $15-20$ & 9 & 0.24 & 0.24 \\
$20-25$ & 11 & 0.19 & 0.43 \\
$25-30$ & 12 & 0.20 & 0.63 \\
$30-40$ & 15 & 0.54 & 1.17 \\
$40-50$ & 15 & 0.91 & 2.08 \\
$50-60$ & 11 & 2.41 & 4.49 \\
$60-70$ & 9 & 4.51 & 9.00 \\
$70-80$ & 12 & 8.32 & 17.32 \\
$80-90$ & 5 & 9.50 & 26.82 \\
$90-100$ & 3 & 11.98 & 38.80 \\
\hline
\end{tabular}

urement, and the largest estimated total length by field observation was nearly $11 \mathrm{~cm}$.

The average time taken for the increment of each 0.5 or $1 \mathrm{~cm}$ in total length is calculated from the measurements of individual growth given in Fig. 9 (Table 4), and a growth curve is figured (Fig. 10). The actual growth curve is probably like the corrected one, for the measurements of individual growth of juveniles in winter are almost lacking in the present data (Fig. 9) and actually they scarcely grow for about three months of that season. Compared with the growth curve of $L$. dimidiatus at Heron Island illustrated by Robertson (1974), juveniles in Shirahama attain the length of $5 \mathrm{~cm}$ about three times as soon as those in Heron Island (Fig. 10). The growth rate in Shirahama, however, suddenly declines afterwards, and then the total length is caught up with by that in Heron Island at the length of about $7 \mathrm{~cm}$ at the time about one year after settlement. The features of the growth afterwards are almost same between the two localities, and the maximum length is at-

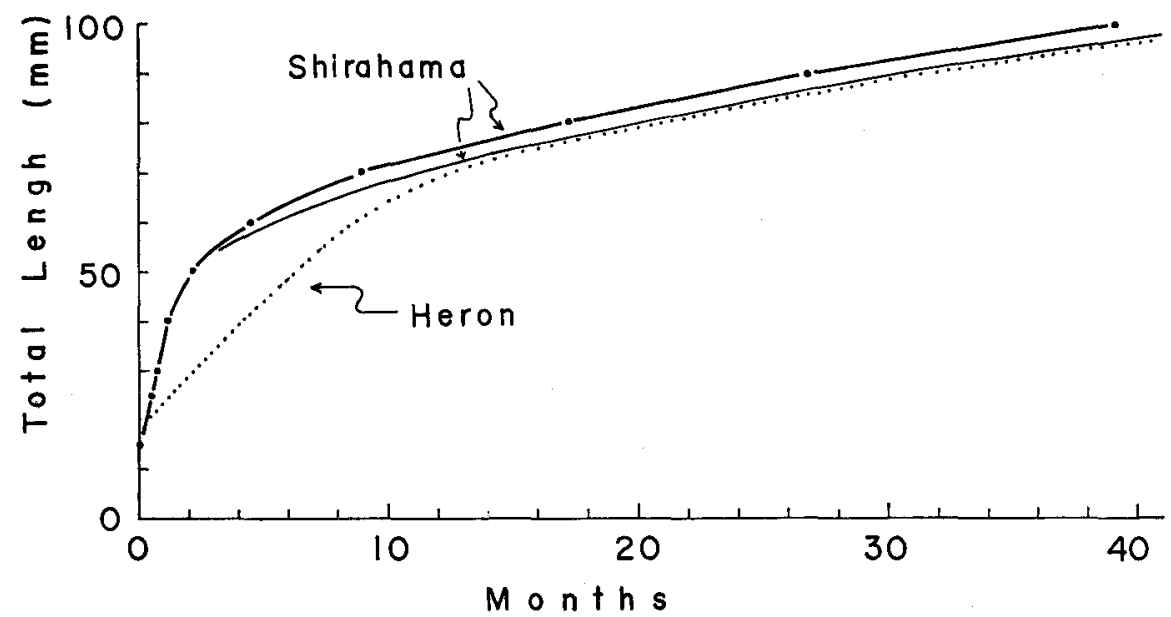

Fig. 10. The growth curve constructed from Table 4 (broad line) and somewhat modified one (narrow line; see text for detail), accompanied with that in Heron Island (dotted line; after Robertson, 1974), 
tained in about 4 years. One individual which was $95 \mathrm{~mm}$ in June 1975 remained in the same place till December 1978, from which the longevity of L. dimidiatus in Shirahama is estimated 6 years or more.

The smallest females seen to spawn were slightly less than $6 \mathrm{~cm}$ total length in Shirahama. Individuals above $6 \mathrm{~cm}$ were often observed spawning. Maturity then is reached at the age of one-year, and one-year old fish are usually functioning as female. Males found during the present study were $94 \mathrm{~mm}$ in average total length, ranging from 79 to $103 \mathrm{~mm}(\mathbf{n}=9)$. It accordingly appears that the sexchange from female to male usually takes place before 3-years old.

In one case one-year old fish was found functioning as male at St. A in summer 1978. In the study area the whole population perished before spring in 1977, and juveniles were newly recruited in autumn of the year. In the next breeding season spawning was not observed until July when an individual, which was the largest (79 $\mathrm{mm}$ ) among the three in the study area, functioned as male. It is evident that the individual had never functioned as female before it functioned as male. It has been known that in L. dimidiatus all males are secondary (derived from females) and primary males (born as such) are absent(Robertson and Choat, 1974; Robertson, 1974), while both primary and secondary males are present in some other labroid fishes (Reinboth, 1975; Choat and Robertson, 1975; Warner and Robertson, 1978; Robertson and Warner, 1978, etc.). As no examination of gonad of the present male was carried out, it is not certain whether the male was really secondary or primary, nor whether it was a prematurational secondary male (Warner and Robertson, 1978) or not.

\section{Summary of the Life History of L. dimidiatus in Shirahama}

A brief summary of the life history of $L$. dimidiatus in relation to the seasonality in Shirahama is given below.

L. dimidiatus is less active during winter, and the "harem system", which implies the maintenance of the male's territory which contains a harem of several females, is restricted to the period from April to December. Pair-spawning occurs in a social group approximately at noon during the period from late May to early September. Out of isolated epipelagic eggs measuring $0.66-0.69 \mathrm{~mm}$ in diameter, larvae of about $1.8 \mathrm{~mm}$ in total length hatch at 30 hours after spawning. In two days after hatching the yolk is almost absorbed. The length of the pelagic larval life is not known precisely, but is roughly estimated about one or two months from the lag between the peaks of spawning and recruitment. Juveniles are recruited at the length of $10 \mathrm{~mm}$ or so during the period from late June to January, mainly from August to October. They are settling in a small range within home ranges of adults for about one month after recruitment, and then become mobile and enlarge their home range to overlap each other. They rapidly attain the length of $5 \mathrm{~cm}$ before December, but the growth is almost hindered during winter. In the next spawning season they are matured usually as female at the length of $6-7 \mathrm{~cm}$, and take part in reproduction. Sex- 
change into male usually occurs shortly before 3-years old at about $9.4 \mathrm{~cm}$ in total length. Smaller females often change the position of their home range, while the home ranges of older females and males are stable during the active period. The longest longevity estimated is more than 6 years. The annual fluctuation of population is considerable, and largely depends on the success of the juvenile recruitment in autumn and the death from cold in winter.

\section{Discussion}

Labroides dimidiatus is a widespread species, ranging from the Indian Ocean to the Pacific, and two main geographic colour variants, the dimidiatus form and the paradiseus form, have been known in it (Randall, 1958; Robertson, 1974). All the specimens from the Indian Ocean are the paradiseus form (Smith, 1949; Eibl-Eibesfeldt, 1959; Springer and Smith-Vaniz, 1972; Potts, 1973), and in the collections from the Marshall Islands and the Philippines the paradiseus form predominates (Randall, 1958), while all the specimens from the Society Islands and Tuamotu Archipelago are the dimidiatus form (Randall, 1958), and it also predominates at Heron Island (Robertson, 1974). All the specimens collected from Shirahama during the present study were regarded as the paradiseus form.

In the population at Heron Island $\left(23^{\circ} 27^{\prime} \mathrm{S} ; 152^{\circ} 05^{\prime} \mathrm{E}\right)$, which mostly consisted of the dimidiatus form, Robertson (1972, 1974; Robertson and Choat, 1974) found stable social groups which comprised a male and a harem of several females living in the male's territory. In contrast to this, Potts (1973) observed territories of solitary juveniles and subadults and of adults in pairs in the population at Aldabra $\left(9^{\circ} 25^{\prime} \mathrm{S} ; 46^{\circ} 21^{\prime} \mathrm{E}\right)$, which consisted of the paradiseus form. Robertson (1974) once attributed this difference in social grouping to the characteristics of the two colour variants, but he later reinvestigated the population at Aldabra Island and confirmed that its social grouping was the same as that of the Heron Island form (Robertson and Hoffman, 1977; Robertson, personal communication). The haremic social grouping was also found in the population of Shirahama, which was composed of the paradiseus form, in the present study. The two colour variants, therefore, seem to have the same social system at the three widely separated locations.

The populations at the three locations have common mating system that pairspawning occurs within a social group (Robertson and Hoffman, 1977; and the present study), and also have common feeding habit that food items are obtained mostly by cleaning other fishes (Potts, 1973; Robertson 1974; Okuno, 1969; Kuwamura, 1976b, 1980a).

The seasonality in the life cycle, however, differs considerably among the three locations. At Aldabra Island, which is closest to the equator among the three, spawning is suggested to occur throughout the year (Robertson and Hoffman, 1977). Minimum water temperatures are lower at Heron Island: sea surface temperatures at the shallow reef flat decline as low as $14^{\circ} \mathrm{C}$ in July, monthly average ranging from $19^{\circ} \mathrm{C}$ (in July) to $27^{\circ} \mathrm{C}$ (in January) (Endean et al., 1956), Although the population 
is stable, and socially and sexually active throughout the year, egg production is restricted to the warmer months, from October to May (Robertson, 1974; Robertson and Hoffman, 1977). Shirahama is situated farthest from the equator among the three locations, and water temperatures decline as low as $10^{\circ} \mathrm{C}$ in January or February, monthly average ranging from about $14^{\circ} \mathrm{C}$ (in January or February) to slightly less than $28^{\circ} \mathrm{C}$ (in August). The population was socially and sexually active only in the warmer months, from April to November or December, and egg production was restricted to 4--5 months from May to September. Moreover, the population was considerably unstable and it almost perished in colder winters. Thus, L. dimidiatus in Shirahama lives near the northernmost and coldest habitat of its range.

In Shirahama spawning begins in late May, when average water temperature usually rises over $20^{\circ} \mathrm{C}$, but it terminates as early as September, although the monthly average of water temperatures is usually still over $20^{\circ} \mathrm{C}$ even in November. During summer and autumn, newly recruited juveniles show rapid growth, but their growth is almost hindered during winter. The early termination of spawning well before winter may be accordingly of adaptive, since it ensures that juveniles will have a growth period of at least two or three months before the sea becomes really cold. Such breeding seasonality has been also known in southern species of marine fishes in British waters (Qasim, 1955).

The growth rate of juveniles in Shirahama is 'considerably higher than that at Heron Island (Fig. 10). The average water temperature in the rapid-growth period of juveniles in Shirahama, from July to November, is a little over $24^{\circ} \mathrm{C}$, and is slightly higher than the anual average of water temperatures at Heron Island, which is a little below $23^{\circ} \mathrm{C}$ (calculated from Endean et al., 1956). Such difference in water temperatures may be in part influencing the growth rate. Moreover, in Shirahama fishes increase both in number of species and abundance at that time of the year (Okuno, 1964; Araga and Tanase, 1966; Kuwamura, 1976a, 1980b), and they will serve as hosts for cleaning (feeding) of $L$. dimidiatus. At Heron Island such seasonal concentration of the host availability is not apparent (Robertson, 1974). The decrease of adult density before or at the beginning of the juvenile recruitment in Shirahama might also favour the growth of juveniles in terms of the food availability.

The rapid growth during summer and autumn in Shirahama makes up for the low growth in winter, and subsequently the one-year old fish in Shirahama are almost as large as that of Heron Island (Fig. 10). The one-year old fish are already matured and predominate in the adult population in the reproductive season in Shirahama. It accordingly appears that the rapid growth of juveniles during summer and autumn may play an important part in the maintenance of population in Shirahama.

It has been documented that the protogynous sex-change in $L$. dimidiatus is controlled by an endogenous mechanism, upon which has been superimposed a mechanism of social control: the male in each harem suppresses the tendency of the females to change sex by actively dominating them, and death of the male releases 
this suppression and the dominant female of the harem changes sex immediately (Robertson, 1972, 1974; Robertson and Choat, 1974). Although the average total length of males, about $94 \mathrm{~mm}$, suggests the protogynous sex-change usually occurring shortly before 3-years old in Shirahama, an one-year old fish was once observed functioning as male in a group comprising three individuals of one-year old. It appears that even an one-year old fish can become a male if there are no older or larger individuals in its vicinity. The population in Shirahama fluctuates on a large scale and there often remains only a small population, sometimes of one-year old fish only, in an area in the reproductive season. In such localities, social control of sex-change may be of advantage for reproduction of population, for it ensures the encounter with the opposite sex even in low density habitat.

Considerable decrease in the adult population occurred in late summer and early autumn as well as in winter in Shirahama. The factors causing the summer and autumn death are not easy to find at present, although the ground swell caused by the typhoon or the exhaustion from spawning may be supposed to be related to the death. It is interesting that the decrease of the adult population occurs coincidentally before or at the beginning of the juvenile recruitment, and that the social organization also becomes somewhat loose at that time. At Heron Island, the juvenile recruitment occurs throughout the year, but mostly in summer (Robertson, 1974). However, the decrease of adult population is not apparently concentrated at that time, nor is any apparent change seen in the social organization. In some territorial pomacentrid fishes, it has been known that the presence of resident adults controls the success of the juvenile recruitment (Sale, 1976), and that juveniles are attacked less strenuously by adults at the time of the year when they normally settle (Moran and Sale, 1977). In L. dimidiatus in Shirahama, the negative correlation is not apparent between densities of resident adults and those of newly recruited juveniles in the limited data at present (Table 3), and the seasonal variation in the tendency to attack juveniles has not yet been sufficiently examined. However, the decrease of adult population, along with the social organization tending to be somewhat loose, is supposed to function in favour of the success of the juvenile recruitment as a consequence.

The mass destruction of the population of L. dimidiatus in winter in Shirahama is thus supposed to be supplied by such features in its life history pattern that (I) spawning terminates well before winter and growth period of juveniles is ensured, (2) the rapid growth in summer and autumn ensures sexual maturation and participation in reproduction at the age of one year in the next breeding season, (3) social control of sex-change assures reproduction even in low density habitat, (4) the concentration of the decrease of adult population in late summer and autumn, as well as the reduced strictness in the social organization, may favour the success of the juvenile recruitment occurring at that time.

Each species has its own range of elasticity in its mode of life, and may have both elastic parts and rigid parts in its mode of life. It can be concluded that, in Shirahama near the northern limit of its range, the tropical labrid L. dimidiatus adopts 
considerable modifications in its life history pattern, mostly according to the environmental seasonality, while the social/mating system and feeding habits are scarcely modified.

\section{Acknowledgements}

I wish to thank members of the staff of the Seto Marine Biological Laboratory for discussing various aspects of this work, and in particular Dr. Eiji Harada for critical reading of the manuscript. I am also grateful to Dr. Hiroya Kawanabe of Kyoto University and Dr. D. Ross Robertson of the Smithsonian Tropical Research Institute for helpful suggestions and reviewing the manuscript. Finally I express my thanks to Mrs. Reiko Kuwamura who helped in so many ways during the preparation of this paper.

\section{REFERENGES}

Araga, C. and H. Tanase. 1966. Inshore fishes of Wakayama Prefecture. Sci. Rep. Jap. Asso. Natu. Conservation, 27: 81-95. (in Japanese).

Araga, C. and H. Tanase. 1968. Further record of winter fish stranding in the vicinity of Seto. Publ. Seto Mar. Biol. Lab., 16: 207-218.

Choat, J.H. and D.R. Robertson. 1975. Protogynous hermaphroditism in fishes of the family Scaridae. p. 263-283. In R. Reinboth (ed.), Intersexuality in the animal kingdom. Springer-Verlag, Berlin.

Eibl-Eibesfeldt, I. 1959. Der Fisch Aspidontus taeniatus als Nachahmer des Putzers Labroides dimidiatus. Z. Tierpsychol., 16: 19-25.

Endean, R., W. Stephenson and R. Kenny. 1956. The ecology and distribution of intertidal organisms on certain islands of the Queensland coast. Aust. J. Mar. Freshwater Res., 7: 317-432.

Hioki, S. 1979. Spawning of labrid fishes in aquarium. Fish Mag., 15: 50-56. (in Japanese).

Kataoka, T., S. Kitamura, M. Sekido and K. Yamamoto. 1970. Coral fishes of the Ogasawara (Bonin) Islands. p. 7-27. In Report on the Marine Biological Expedition to the Ogasawara (Bonin) Island, 1968. Toba Aquarium, Asahi Shinbun Pub. Co. (in Japanese).

Kimura, S. 1965 . Underwater research in the Iki and Tsushima marine park area. Sci. Rep. Jap. Asso. Natu. Conservation, 19: 138-144. (in Japanese).

Kuwamura, T. 1976a. Seasonal occurrence of fishes in the interstice of shrub corals on the rocky reef of Shirahama, Japan. Nankiseibutsu, 18: 15-22. (in Japanese with English summary).

Kuwamura, T. 1976b. Different responses of inshore fishes to the cleaning wrasse, Labroides dimidiatus, as observed in Shirahama. Publ. Seto Mar. Biol. Lab., 23: 119-144.

Kuwamura, T. 1980a. Cleaning symbiosis among marine organisms at the shallow rocky reefs in Shirahama. Nankiseibutsu, 22: 29-32. (in Japanese).

Kuwamura, T. 1980b. Seasonal occurrence of fishes at inshore rocky reefs in Shirahama, southern Japan. Japan. J. Ichthyol., 27: 243-248. (in Japanese with English summary).

Mito, S. 1962. Pelagic fish eggs from Japanese waters-VI Labrina. Sci. Bull. Fac. Agr., Kyushu Univ., 19: 493-502. (in Japanese with English summary).

Moran, M.J. and P.F. Sale. 1977. Seasonal variation in territorial response, and other aspects of the ecology of the Australian temperate pomacentrid fish Parma microlepis. Mar. Biol., 39: 121128.

Nakamura, M. 1934. On the tide-pool fish in the vicinity of Kominato Laboratory. Yoshokukaishi, 4: 191-203. (in Japanese).

Okuno, R. 1964. On the reef fishes of Tanabe Bay compared with those on the coral reefs of Marshall Islands reported by Hiatt and Strasburg (1960). Physiol. Ecol., 12: 272-285. (in Japanese with English summary). 
Okuno, R. 1969. Cleaning behaviors of the rainbow wrasse, Labroides dimidiatus. II. Jap. J. Ecol., 19: 217-222. (in Japanese with English summary).

Potts, G.W. 1973. The ethology of Labroides dimidiatus (Cuv. \& Val.) (Labridae, Pisces) on Aldabra. Anim. Behav., 21: 250-291.

Qasim, S.Z. 1955. Time and duration of the spawning season in some marine teleosts in relation to their distribution. J. Cons. Internat. Explor. Mer., 21: 144-155.

Randall, J.E. 1958. A review of the labrid fish genus Labroides, with descriptions of two new species and notes on ecology. Pac. Sci., 12: 327-347.

Randall, J.E. and V.G. Springer. 1975. Labroides pectoralis, a new species of labrid fish from the tropical western Pacific. Uo, 25: 4-11.

Reinboth, R. 1975. Spontaneous and hormone-induced sex-inversion in wrasses (Labridae). Pubbl. Staz. Zool. Napoli, 39 (Supple.): 550--573.

Robertson, D.R. 1972. Social control of sex reversal in a coral-reef fish. Science, 177: 1007-1009.

Robertson, D.R. 1974. A study of the ethology and reproductive biology of the labrid fish, Labroides dimidiatus, at Heron Island, Great Barrier Reef. Ph. D. Thesis, University of Queensland, $295 \mathrm{pp}$.

Robertson, D.R. and J.H. Choat. 1974. Protogynous hermaphroditism and social systems in labrid fish. Proc. Int. Symp. Coral Reef, 2nd., 1:217-225.

Robertson, D.R. and S.G. Hoffman. 1977. The role of female mate choice and predation in the mating systems of some tropical labreid fishes. Z. Tierpsychol., 45: 298-320.

Robertson, D.R. and R.R. Warner. 1978. Sexual patterns in the labroid fishes of the Western Caribbean, II: The parrotfishes (Scaridae). Smithson. Contrib. Zool., 255: 1-26.

Sale, P.F. 1976. The effect of territorial adult pomacentrid fishes on the recruitment and survival of juveniles on patches of coral rubble. J. exp. mar. Biol. Ecol., 24: 297-306.

Smith, J.L.B. 1949. The sea fishes of southern Africa. Central News Agency Ltd., Cape Town, 550 pp.

Springer, V.G. and W.F. Smith-Vaniz. 1972. Mimetic relationships involving fishes of the family Blenniidae. Smithson. Contrib. Zool., 112: 1-36.

Warner, R.R. and D.R. Robertson, 1978. Sexual patterns in the labroid fishes of the Western Caribbean, I: The wrasses (Labridae). Smithson. Contrib. Zool., 254: 1-27.

Yoshino, T., S. Nishijima and S. Shinohara. 1975. Catalogue of fishes of the Ryukyu Islands. Bull. Science \& Engineering Div., Univ. of the Ryukyus. Math \& Nat. Sci., 20: 61-118. (in Japanese with English summary). 